Original research

\title{
Validation to the Spanish of the Jefferson empathy scale health professions students version and its psychometric properties in nursing students
}

\author{
María José Díaz Valentín ${ }^{\mathrm{a}, *}$, Margarita Garrido Abejar ${ }^{\mathrm{a}}$, Rosa María Fuentes Chacón ${ }^{\mathrm{a}}$, \\ María Dolores Serrano Parra ${ }^{\mathrm{a}}$, María Elisa Larrañaga Rubio ${ }^{\mathrm{b}}$, Santiago Yubero Jiménez \\ ${ }^{a}$ Department of Nursing, University of Castilla-La Mancha, Cuenca, Spain \\ ${ }^{\mathrm{b}}$ Department of Psychology, University of Castilla-La Mancha, Cuenca, Spain
}

\section{A R T I C L E I N F O}

\section{Keywords:}

Empathy

Jefferson scale of empathy

Nursing students

Psychometric properties

\begin{abstract}
A B S T R A C T
The ability to empathize with patients has a positive effect on health outcomes and quality of care. This study aimed to evaluate the psychometric characteristics of the Spanish version of the Jefferson Scale of EmpathyHealth Profession Student version (JSE-HPS) in a sample of 422 nursing students and to compare their factorial structure with that of the original scale. In this study, the Cronbach $\alpha$ value was 0.828 . These analyses showed that the scale has a factorial structure with three dimensions and all the items loaded adequately $(>0.36)$ except for item 18 (0.266). The main factor, Perspective taking grouped 10 items; the second factor, 'Compassionate caré, grouped 6 items, and the third factor, Standing in the patient's shoes, grouped 3 items; 42.2\% of the variance was explained. The results of the confirmatory factor analysis suggest that the Spanish version of the JSE-HPS is a valid and reliable way to evaluate the empathic capacity of nursing students.
\end{abstract}

\section{Introduction}

In clinical practice, nurses are in contact with the human suffering derived from patients' personal experiences with the pain, uncertainty, anxiety, and anguish generated by the loss of health. Understanding these experiences is essential to providing quality care and attention focused on the needs of patients (Kelley et al., 2014). In this context, care is at the heart of nursing practice and is understood as a process based on interpersonal sensitivity and closeness (Finfgeld-Connett, 2008; Percy and Richardson, 2018).

In this sense, empathy is recognized as a key element in the care and therapeutic relationships between patients and health professionals (Brunero et al., 2010; Fields et al., 2011; Ward et al., 2009). Studies carried out in clinical fields have shown that empathic relationships have multiple benefits; they indicate a close relationship between satisfaction and quality of care (Kim et al., 2004) and have a positive effect on patients' health by decreasing their stress levels (Del Canale et al., 2012). It also increases treatment adherence, encourages the responsible use of healthcare resources, and is a buffer against conflicts between patients and professionals (Del Canale et al., 2012; Hojat and LaNoue, 2014; Kim et al., 2004). Moreover, although inconclusive, there are studies indicating that more empathic health professionals perceive less stress and experience greater satisfaction in their work (Reynolds and Scott, 2000; Ward et al., 2012).

Another important concept related to empathy, as well as to interpersonal relationships, is emotional intelligence (EI), defined as the ability to perceive and understand one's own emotions, as well as those of others, which it has proven to be an important component in nursing education (Orak et al., 2016). It is also notable that in clinical settings, nurses have to manage the emotions of patients and their respective families, as well as those of their colleagues. In fact, resilience may have a mitigating effect on the stress and exhaustion caused by the continuing exposure to the aforementioned demands (Thomas and Asselin, 2018).

Despite its clinical usefulness, the concept of empathy is controversial and is difficult to define; for most authors it is a multidimensional concept that includes cognitive and affective aspects (Hoffman, 2002; Hojat et al., 2001). In clinical settings, empathy has been characterized as a fundamentally cognitive attribute that involves comprehending patients' concerns and feelings as well as communicating this understanding to them (Hojat and LaNoue, 2014). Research shows that the benefits of empathy would not be possible if

\footnotetext{
*Corresponding author. Department of Nursing. University of Castilla-La Mancha, Edificio "Melchor Cano" C/ Santa Teresa Jornet s/n, 16071, Cuenca, Spain.

E-mail addresses: mariajose.diaz@uclm.es, mjosediazvalentin@hotmail.com (M.J. Díaz Valentín), margarita.garrido@uclm.es (M. Garrido Abejar), rosa.fuentes@uclm.es (R.M. Fuentes Chacón), dolores.serrano@uclm.es (M.D. Serrano Parra), Elisa.Larranaga@uclm.es (M.E. Larrañaga Rubio), Santiago.Yubero@uclm.es (S. Yubero Jiménez).
} 
professionals were unable to convey to patients the fact that they understand their situation, perceptions, and feelings in a professional and cordial manner. Thus, patients perceive empathy as the understanding and acceptance of their feelings by the health professional (Hojat et al., 2001). Furthermore, when patients feel understood, their relationship with their health professionals improves, they better explain their symptomatology and needs, and they participate more actively in therapeutic processes (Hojat and LaNoue, 2014). However, in other contexts the emphasis is placed on affective or emotional attributes which are understood as a vicarious emotional responses that are experienced before the emotional experiences of others (Hoffman, 2002). Nonetheless, despite the differences in conceptualization, it is recognized that both aspects are interrelated and that, in clinical situations, both act to the benefit of the patient (Hojat and LaNoue, 2014).

Measuring empathy is complex and the tools for assessing it are varied (Fields et al., 2011; Yu and Kirk, 2009). In clinical settings, the most widely used scale is the one proposed by Hojat et al. (2001), which is internationally recognized as the Jefferson Scale of Physician Empathy (JSPE). The scale was initially developed to measure empathy in physicians, and it is now distributed internationally. Its different versions have been translated into more than 45 languages, and it is used in more than 70 countries (Hojat and LaNoue, 2014). The importance of empathy in the patient-nurse relationship has favored a growing interest in developing instruments that allow its evaluation (Yu and Kirk, 2009). Specifically, it is important to measure and understand the level of empathy among nursing students in order to promote effective educative strategies to develop this essential ability in the quality care of patients (Williams et al., 2016).

Analysis of the JSPE scale revealed that it has a four-dimensional factorial structure (Hojat et al., 2001). However, subsequent studies by the same author, applying confirmatory factor analysis (CFA), reduced this factorial structure to three dimensions (Hojat and LaNoue, 2014). The first factor, Perspective taking, is the predominant factor in the scale and refers to the cognitive aspects of empathy. The second factor, Compassionate caré, is characterized by a combination of cognitive and affective aspects of empathy and is also considered an essential factor in professional relationships with patients. The third factor,'Standing in the patient's shoes, is a concept that is inverse to emotional detachment (Hojat et al., 2001). This factorial structure has been tested in multiple versions of the scale: JSE-HP for health professionals, JSE-S for medical students and JSE-HPS for health profession students. Table 1 presents the studies carried out to date with different health-profession students, which either include confirmatory factor analysis as recommended by Hojat (2016) or that were undertaken with nursing students (AlcortaGarza et al., 2016; Ferreira-Valente et al., 2016; Hojat and LaNoue, 2014; Hojat et al., 2001; Hsiao et al., 2013; Leombruni et al., 2014; Magalhães et al., 2011; McMillan and Shannon, 2011; Montanari et al., 2015; Ryu and Bang, 2016; Tavakol et al., 2011; Ward et al., 2009; Wen et al., 2013; Williams et al., 2013).

From the Thomas Jefferson University (Center for Research in Medical Education and Health Care) recommend that the JSE-HP and JSE-HPS be used for research involving nurses and nursing students, respectively (Hojat, 2016). The characteristics of these versions and their potential application in the field of nursing education and practice, has aroused the interest among nurses from all over the world. The JSE-HPS, has been used in different contexts (Fields et al., 2011; Kiersma et al., 2013; Petrucci et al., 2016; Williams et al., 2013) and has been validated and translated into different languages including Italian (Montanari et al., 2015), Chinese (Hsiao et al., 2013), Korean (Ryu and Bang, 2016), and Tamil (Jeyashree et al., 2017). However, there is no a validated Spanish version of the JSE-HPS in nursing students.

\subsection{Aim of the study}

This study set out to examine the following points:
- To translate and culturally adapt the JSE-HPS in a sample of university nursing students in the Spanish language context and evaluate its psychometric properties.

- To compare our results with those provided in other studies in health-profession students.

- To explore the relationship between empathy, emotional intelligence and resilience as conceptually relevant measures.

\section{Methods}

\subsection{Study design}

A descriptive cross-sectional study was carried out between 2015 and 2016 to test the validity and psychometric properties of the Spanish version of the JSE-HPS with Spanish university nursing students.

\subsection{Sampling, setting and instruments}

A sample of convenience was selected from among the students enrolled in the nursing undergraduate degree course at the University of Castilla La Mancha during 2015-2016. According to Spanish Law, university nursing programs last four years, with the curriculum offering a theoretical course in the first year and practical clinical experience, mainly in university hospitals and primary-care settings, in the following three years. Our inclusion criterion was that nursing students should have clinical experience, since the instrument requires having had contact with patients in order to complete the scale.

Nursing students who met the inclusion criteria were 557 students from the 2nd, 3rd and 4th academic courses (1-2 months, 2-6 months and $>6$ months of practice respectively). Four hundred twenty-two students completed the questionnaire $(75.76 \%$ of response rate), the sample size was greater than the estimated size (228 students). Each participant completed questionnaires relating to the sociodemographic variables (i.e., sex and age), months of clinical experience, and the following scales:

- The Jefferson Scale of Empathy Health Profession Student version (JSE- HPS) (Hojat, 2016) used by Fields et al. (2011), to evaluate the nursing student's empathy. As in the original, this scale comprises 20 items; each one is evaluated using a 7-point Likert-type scale ( 1 = strongly disagree, $7=$ strongly agree). Ten of these items are written positively (e.g. 'Health care providers should try to stand in their patients' shoes when providing care to them') and the other 10 are negatively worded and must be reversed (e.g. 'Asking patients about what is happening in their personal lives is not helpful in understanding their physical complaints'). Negative items are used to avoid social desirability and acquiescence in the responses. The scale ranges from 20 to 140 points, with higher scores indicating greater empathic orientation (Hojat et al., 2001).

- The Brief Emotional Intelligence Scale (BEIS-10) (Davies et al., 2010), translated into Spanish (Martín de Benito and Guzmán Luján, 2012), to evaluate emotional intelligence (EI). This scale consists of 10 items and each one is evaluated using a Likert scale (Totally agree $=5$, Totally disagree $=1$ ); it has a range of $5-50$ points, with higher scores being interpreted as representative of a better EI.

- The Connor-Davidson Resilience Scale (CD-RISC-10) (Connor and Davidson, 2003), validated for use in Spanish (Serrano-Parra et al., 2013) to assess resilience. This scale comprises 10 items structured on a Likert scale (Almost always $=4$, Often $=3$, Sometimes $=2$, Rarely $=1$, Not at all $=0$ ). This scale ranges from 0 to 40 , has no established cutoff point; higher scores are interpreted as indicative of increased resilience.

\subsection{Cultural adaptation}

Approval to use the JSE-HPS for the validation process in the 
Table 1

Relationship between studies on health-profession students which included CFA or nursing students.

\begin{tabular}{|c|c|c|c|}
\hline Reference & Country & Scale and population & Type of analysis and factors \\
\hline Alcorta-Garza et al. (2016) & $\begin{array}{l}\text { Spain, Mexico, Colombia, } \\
\text { Bolivia, Argentina. }\end{array}$ & $\begin{array}{l}\text { JSE-HP } \\
\mathrm{N}=715 \\
\text { Medicine students }\end{array}$ & $\begin{array}{l}\text { EFA/CFA } \\
\text { F1 Perspective taking } 2,4,5,9,10,13,15,16,17,20 \\
\text { F2 Compassionate care: } 1,7,8,11,12,14,19 \\
\text { F3 Standing/Walking in the patient's shoes: } 3,6,18\end{array}$ \\
\hline Ferreira-Valente et al. (2016) & Spain & $\begin{array}{l}\text { JSE-S } \\
\mathrm{N}=1104 \\
\text { Medicine students }\end{array}$ & $\begin{array}{l}\text { EFA/CFA } \\
\text { F1 Perspective taking: } 2,4,5,9,10,13,15,16,17,20 \\
\text { F2 Compassionate care: } 1,7,8,11,12,14,18,19 \\
\text { F3 Standing in the patient's shoes: } 3,6 \\
\text { EFA }\end{array}$ \\
\hline Hojat et al. (2001) & USA & $\begin{array}{l}\text { JSPE } \\
\mathrm{N}=193 \\
\text { Medicine students. }\end{array}$ & $\begin{array}{l}\text { F1 Physician's view from patient's perspective.17, 5, 1, 8, 4, 15, 2, 7, 9, } 11 \\
\text { F2 Understanding patient's experiences, feelings and clues:13, 10, 16, 12, 18, } 19 \\
\text { F3 Ignoring emotions in patient care } 6,14 \\
\text { F4 Thinking like the patient: } 18,3\end{array}$ \\
\hline Hojat and LaNoue (2014) & USA & $\begin{array}{l}\text { JSE- S } \\
\mathrm{N}=2612 \\
\text { Medicine students }\end{array}$ & $\begin{array}{l}\text { EFA/CFA } \\
\text { F2 Compassionate care: } 11,14,8,12,1,7,19 \\
\text { F3 Walking in patient's shoes: } 6,3\end{array}$ \\
\hline Hsiao et al. (2013) & $\begin{array}{l}\text { China } \\
\text { Taiwan }\end{array}$ & $\begin{array}{l}\text { JSE-HPS } \\
\mathrm{N}=613 \\
\text { Nursing students }\end{array}$ & $\begin{array}{l}\text { FFA } \\
\text { F2 Compective taking: } 10,16,4,13,20,9,2,17,15,5 \text {, } \\
\text { F3 Standing in the patient's shoes: } 6,3\end{array}$ \\
\hline Leombruni et al. (2014) & Italy & $\begin{array}{l}\text { JSE- } \mathrm{S} \\
\mathrm{N}=257 \\
\text { Medicine students }\end{array}$ & $\begin{array}{l}\text { EFA/CFA } \\
\text { F1 Perspective taking 16, 13, 20, 15, 10, 2, 4, 9, 5, } 17 \\
\text { F2: Compassionate care: } 11,8,7,14,18,1,19,12 \\
\text { F3 Standing in the patient's shoes: } 3,6 \\
\text { Item } 18 \text { no loading }\end{array}$ \\
\hline $\begin{array}{l}\text { McMillan and Shannon } \\
\text { (2011) }\end{array}$ & USA & $\begin{array}{l}\text { JSPE-R Nursing } \\
\mathrm{N}=598 \\
\text { Nursing students }\end{array}$ & $\begin{array}{l}\text { EFA/CFA } \\
\text { F1 Emotional Engagement/Compassionate Care: 13, 16, 20, 14, 12, 11, 8, 7, } 1 \\
\text { F2 Perspective taking: } 2,4,5,9,10,15,17 \\
\text { F3 Standing in the patient's shoes: } 3,18,6\end{array}$ \\
\hline Magalhães et al. (2011) & Portugal & $\begin{array}{l}\text { JSPE- } \mathrm{S} \\
\mathrm{N}=476 \\
\text { Medicine students }\end{array}$ & $\begin{array}{l}\text { EFA/CFA } \\
\text { F1 Compassionate care: } 14,8,1,20,10,13,7,2,11,12 \\
\text { F2 Perspective taking: } 17,9,16,15,5,4,18 \\
\text { F3 Put oneself in someone's shoes: } 6,3,19\end{array}$ \\
\hline Montanari et al. (2015) & Italy & $\begin{array}{l}\text { JSE-HPS } \\
\mathrm{N}=797 \\
\text { Nursing students }\end{array}$ & $\begin{array}{l}\text { EFA/CFA } \\
\text { F1 Care sensitivity: } 14,11,16,12,7,8,20,19,1,4,2 \\
\text { F2 Patients' perspective understanding: } 9,17,10,15,13,5 \\
\text { F3 Standing in the patient's shoes: } 6,3,18\end{array}$ \\
\hline Ryu and Bang (2016) & Korean & $\begin{array}{l}\text { JSE-HPN }=253 \\
\text { Nurses }\end{array}$ & $\begin{array}{l}\text { EFA/CFAF1 Perspective taking: } 16,15,13,10,9,5,4,2,17,20 \mathrm{~F} 2 \text { Compassionate } \\
\text { care: } 1,7,8,11,12,14 \mathrm{~F} 3 \text { Standing in the patient's shoes: } 6,3\end{array}$ \\
\hline Tavakol et al. (2011) & UK & $\begin{array}{l}\text { JSPE } \\
\mathrm{N}=853 \\
\text { Medicine students }\end{array}$ & $\begin{array}{l}\text { EFA/CFA } \\
\text { F1 Compassionate care: } 20,14,16,12,11,7,2,19,13,10 \\
\text { F2 Perspective taking: } 17,9,5,4 \\
\text { F3 Emotional detachment: } 6,3,18\end{array}$ \\
\hline Ward et al. (2009) & USA & $\begin{array}{l}\text { JSE- Nursing } \\
\mathrm{N}=333 \\
\text { Nursing students }\end{array}$ & $\begin{array}{l}\text { FFA } \\
\text { F1 Perspective taking: } 16,10,4,2,20,13,9,5,15,17 \\
\text { F3 Standing in the patient's shoes: } 6,3 \\
\text { Items } 1 \text { and } 18 \text { no loading }\end{array}$ \\
\hline Wen et al. (2013) & China & $\begin{array}{l}\text { JSPE-S } \\
\mathrm{N}=902 \\
\text { Medicine students }\end{array}$ & $\begin{array}{l}\text { EFA/CFA } \\
\text { F1 Perspective taking: } 16,15,17,20,10,13,4,2,9,5 \\
\text { F2 Compassionate care: } 14,11,12,8,7,1,19 \\
\text { F3 Standing in the patient's shoes: } 6,3 \\
\text { Item } 18 \text { no loading }\end{array}$ \\
\hline Williams et al. (2013) & Australia & $\begin{array}{l}\text { JSPE- HPS } \\
\mathrm{N}=330 \\
\text { Paramedic students }\end{array}$ & $\begin{array}{l}\text { EFA/CFA } \\
\text { F1 Compassionate care: } 14,11,7,12,3,19,6,8,1 \\
\text { F2 Perspective taking: } 16,13,20,10,17,15,9 \\
\text { Remove items } 2,5,18\end{array}$ \\
\hline
\end{tabular}

EFA: Exploratory factor analysis. CFA: Confirmatory factor analysis.

Spanish language context was obtained from the Thomas Jefferson University (Center for Research in Medical Education and Health Care). To produce the Spanish version of the JSE-HPS in this study we translated, culturally adapted, and validated it following previously published recommendations (Reichenheim and Moraes, 2007). Each of these steps was developed by a panel of three bilingual Spanish-English experts ( 1 nurse, 1 doctor, and 1 clinical psychologist) who first verified the conceptual relevance of the items on the instrument. Semantic equivalence was tested by comparing each expert's independent translation. The discrepancies identified were minimal and related only to words that can have different translations in Spanish. The first Spanish version was produced by consensus and this was then back-translated by a native English-speaking translator. The panel members subsequently compared this version with the original (the concordance exceeded 95\%) and thus, produced a preliminary version which was tested in a pilot study with 30 nursing students from different bachelor's 
degree courses. At the end of the preliminary test, the students were asked about the clarity of each item and if they had any difficulties in understanding the items. Subsequent analysis confirmed that there were no comprehension problems or ambiguities in the interpretation of the questionnaire and so the final version of the questionnaire was prepared, together with instructions for the investigators administrating it.

\subsection{Data analysis}

Reliability: To analyze the internal consistency of the scale, we used Cronbach's $\alpha$ coefficient. Test-retest reliability, was examined in a subsample of 51 nursing students, selected randomly from all the sample, who completed this scale (JSE-HPS) 2 weeks later.

Construct validity: Using exploratory factor analysis (EFA), we aimed to ascertain how many factors underlie the scale, and whether the factorial structure matched that of the original version used for the North American population. We used the Barlett sphericity test and the Kaiser-Meyer-Olkin (KMO) index to assess the adequacy of the factorial solution and a varimax rotation to improve the allocation of items to the different factors. Using confirmatory factor analysis (CFA) and the maximum likelihood method, we evaluated the fit of the models suggested by the EFA. The following indices were used: the penalizing function $\left(\chi^{2} /\right.$ degrees of freedom [df]), with values lower than 3 indicating good fit; the comparative fit index (CFI), which ranges from 0 to 1 and with a minimum good fit value of 0.90 ; and the standardized root mean square residual (SRMR) index, with values lower than 0.08 indicating a good fit.

Convergent validity: Pearson correlation coefficient was used to test the relationships between empathy and two related constructs, emotional intelligence (BEIS-10 scale) and resilience (CD-RISC 10 scale). We assessed emotional intelligence because studies indicate that it allows one to better interpret and manage one's own and others' emotions, and because it also favors a more effective relationship with patients (Espinoza-Venegas et al., 2015; Extremera Pacheco, 2004). In terms of resilience, recent studies indicate that it reduces professional stress and improves empathy in healthcare providers (Kemper and Khirallah, 2015; Thomas and Asselin, 2018).

\subsection{Ethical considerations}

The Ethics Committee at the University Castilla-La Mancha approved the study. Participation of the students was voluntary, and the researchers committed to treat the data confidentially; the data were processed anonymously.

\section{Results}

The study included 422 students, of whom $19.1 \%$ were male; the mean age was $22.86 \pm 4$ years. Table 2 shows the sociodemographic and general characteristics of the sample.

\subsection{Reliability analysis}

The Cronbach $\alpha$ coefficient was 0.828 , and this increased to 0.846 when item 18 was removed. Test-retest reliability showed an intraclass correlation coefficient of $0.716(95 \% \mathrm{CI}=0.590-0.818)$. Pearson correlation coefficients between each item and the total score of the JSEHPS showed statistical significance $(\mathrm{p}<0.001)$ except for item 18 ('Health care providers should not allow themselves to be influenced by strong personal bonds between their patients and their family members'). The item-scale correlation range was 0.342 (item 6, 'Because people are different, it is difficult to see things from patients' perspectives') to 0.645 (item 16, 'Health care providers' understanding of the emotional status of their patients, as well as that of their families is one important component of the health care provider-patient relationship').

\subsection{Construct validity}

The EFA examined the major components in the JSE-HPS. Initially the factorial solution converged on four factors that explained $51.49 \%$ of the variance, but following Hojat (2016) recommendations, we limited the number of factors to three, which also made our results more comparable to similar studies. By forcing the number of factors to three, the variance reduced to $46.18 \%$ and the resulting factorial solution was adequate $(\mathrm{KMO}=0.869)$ and the Barlett sphericity test was significant $\left(\chi^{2}=2.458 .6, \mathrm{df}=190 ; \mathrm{p}<0.000\right)$. The first factor, Perspective taking, is the most important factor because it evaluates the cognitive element of empathy; it included ten items $(9,16,13,17,20$, $15,10,4,5$, and 2 ) and explained $27.358 \%$ of the variance and Cronbach $\alpha$ coefficient was 0.865 . The second factor, Compassionate care, evaluates the emotional dimension of empathy, and included 6 items $(12,11,8,14,7$, and 1$)$; these explained $12.528 \%$ of the variance and Cronbach $\alpha$ coefficient was 0.736 . Finally, the third factor, Standing in the patient's shoes, assessed emotional attachment and included three items $(3,6$, and 19$)$, and explained $6.301 \%$ of the variance and Cronbach $\alpha$ coefficient was 0.508 . All the items obtained factorial loads higher than 0.3 , except for item 18 (see Table 3). In terms of AFC, the 20 items were modelled as a function of the three underlying factors from the exploratory analysis. The resulting model (see Fig. 1) had an acceptable fit $\left(\chi^{2}=391.04\right.$, df $=149, \mathrm{p}<0.01$, CFI $=0.95$, root mean square error of approximation $=0.046$ ).

The inter-item correlation in items included in Standing in the patient's shoes dimension (items 3,6,19) showed less number of statistically significant correlations and lower correlation values compared to the other dimensions.

\subsection{Convergent validity}

Pearson correlation coefficient showed statistical significance between empathy and emotional intelligence $(p=0.000)$, on the one hand, and resilience $(p=0.037)$, on the other. (See Table 4).

\section{Discussion}

This study constitutes the first Spanish validation of the JSE-HPS with nursing students. This validation of the Spanish version of the JSEHPS shows that it is a reliable, valid, and appropriate instrument for evaluating empathy among nursing students. This scale is widely and internationally accepted for its usefulness in nursing education and practice, as shown by the numerous research studies that apply it (Fields et al., 2011; Hsiao et al., 2013; Montanari et al., 2015; Petrucci

Table 2

Sociodemographic and general sample characteristics.

\begin{tabular}{|c|c|c|c|c|}
\hline Characteristics & Total & Male & Female & $\mathrm{p}$ \\
\hline Gender & 422 & $19.1 \%$ & $80.9 \%$ & \\
\hline Age & $22.86 \pm 4.00$ & $23.43 \pm 3.69$ & $22.69 \pm 4.08$ & 0.119 \\
\hline Empathy & $118.09 \pm 12.20$ & $117.541 \pm 12.88$ & $118.23 \pm 12.04$ & 0.639 \\
\hline Emotional intelligence & $38.57 \pm 4.62$ & $39.318 \pm 5.41$ & $38.39 \pm 4.38$ & 0.093 \\
\hline Resilience & $28.52 \pm 5.73$ & $29.29 \pm 6.18$ & $28.32 \pm 5.60$ & 0.149 \\
\hline
\end{tabular}


Table 3

Factor-loading for EFA with three fixed factors of the Spanish version of the Jefferson scale empathy-health profession students (JSE-HPS).

\begin{tabular}{|c|c|c|c|}
\hline Items & PT & CC & SPS \\
\hline 9. Health care providers should try to stand in their patients' shoes when providing care to them. & .783 & -.097 & .076 \\
\hline $\begin{array}{l}\text { 16. Health care providers' understanding of the emotional status of their patients, as well as that of their families is one important component of the } \\
\text { health care provider - patient relationship. }\end{array}$ & .702 & .139 & .017 \\
\hline 10. Patients value a health care provider's understanding of their feelings which is therapeutic in its own right. & .685 & -.099 & .097 \\
\hline $\begin{array}{l}\text { 13. Health care providers should try to understand what is going on in their patients' minds by paying attention to their non-verbal cues and body } \\
\text { language. }\end{array}$ & .684 & .120 & -.031 \\
\hline 17. Health care providers should try to think like their patients in order to render better care. & .672 & .043 & -.072 \\
\hline 20. I believe that empathy is an important factor in patients' treatment. & .638 & .163 & .018 \\
\hline 5. A health care provider's sense of humor contributes to a better clinical outcome. & .637 & -.152 & -.028 \\
\hline 4. Understanding body language is as important as verbal communication in health care provider - patient relationships. & .630 & .041 & .028 \\
\hline 15. Empathy is a therapeutic skill without which a health care provider's success is limited. & .592 & .245 & .001 \\
\hline 2. Patients feel better when their health care providers understand their feelings. & .580 & -.015 & -.007 \\
\hline 18. Health care providers should not allow themselves to be influenced by strong personal bonds between their patients and their family members. & -.267 & -.020 & .266 \\
\hline 12. Asking patients about what is happening in their personal lives is not helpful in understanding their physical complaints. & .074 & .785 & .050 \\
\hline 7. Attention to patients' emotions is not important in-patient interview. & -.073 & .713 & -.101 \\
\hline $\begin{array}{l}\text { 11. Patients' illnesses can be cured only by targeted treatment; therefore, health care providers' emotional ties with their patients do not have a } \\
\text { significant influence in treatment outcomes. }\end{array}$ & .036 & .710 & .047 \\
\hline 14. I believe that emotion has no place in the treatment of medical illness. & .109 & .684 & -.023 \\
\hline 8. Attentiveness to patients' personal experiences does not influence treatment outcomes. & .107 & .681 & .065 \\
\hline 1. Health care providers' understanding of their patients' feelings and the feelings of their patients' families does not influence treatment outcomes. & .023 & .373 & .211 \\
\hline 3. It is difficult for a health care provider to view things from patients' perspectives. & .119 & -.077 & .835 \\
\hline 6. Because people are different, it is difficult to see things from patients' perspectives. & .006 & .040 & .772 \\
\hline 19. I do not enjoy reading non-medical literature or the arts. & -.015 & .268 & .366 \\
\hline
\end{tabular}

EFA: exploratory factor analysis. PT: Perspective Taking. CC: Compassionate Care. SPS: Standing in the patient's Shoes.

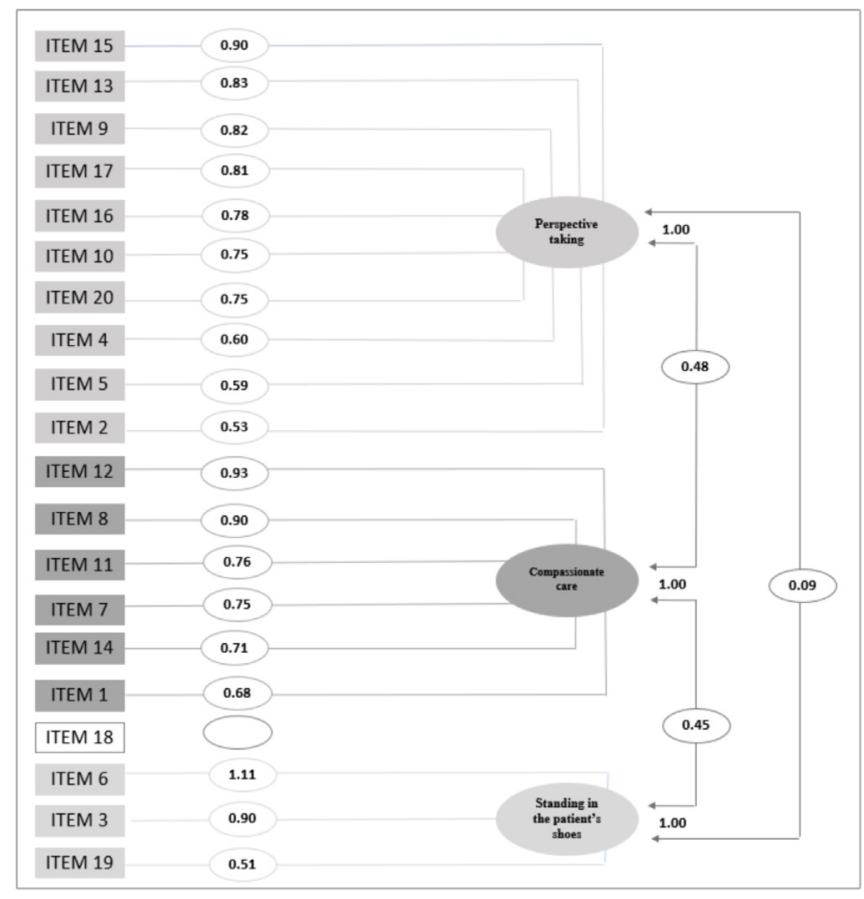

Fig. 1. Model for the confirmatory factor analysis.

Table 4

Pearson correlation between empathy, emotional intelligence, and resilience.

\begin{tabular}{lll}
\hline & Empathy & Emotional Intelligence \\
\hline Emotional Intelligence & $.201^{* *}$ & \\
Resilience & $.103^{*}$ & $.518^{* *}$ \\
\hline
\end{tabular}

${ }^{*} \mathrm{p}<0.05 .{ }^{* *} \mathrm{p}<0.01$.

et al., 2016; Williams et al., 2013).

Using EFA and CFA, we found a three-dimensional factorial structure in this study, which coincides with the finding of in other published work. In general, and regardless of the JSE version used, the studies we consulted had a three-dimensional structure. 'Perspective taking', 'Compassionate care', and 'Standing in the patient's shoes' (Alcorta-Garza et al., 2016; Hojat and LaNoue, 2014; Hsiao et al., 2013; Leombruni et al., 2014; Magalhães et al., 2011; McMillan and Shannon, 2011; Montanari et al., 2015; Tavakol et al., 2011; Ward et al., 2009; Wen et al., 2013), while alternative factorial structures were less frequently found (Fjortoft et al., 2011; Preusche and Wagner-Menghin, 2013; Suh et al., 2012; Williams et al., 2013).

However, there were some differences in the items included in each factor. In our CFA, virtually all the items behaved in a similar way to those in the study published by Hojat (2016). However, in our case, item 19 ('I do not enjoy reading non-medical literature or the arts'), loaded in the Standing in the patient's shoes factor, while in the majority of studies, it did so in the Compassionate care factor (Alcorta-Garza et al., 2016; Ferreira-Valente et al., 2016; Hojat and LaNoue, 2014; Hsiao et al., 2013; Ward et al., 2009; Wen et al., 2013). Additionally, item 18, 'Health care providers should not allow themselves to be influenced by strong personal bonds between their patients and their family members', was the only that did not correlate with item-to-total scale correlations and showed a particularly low saturation level in this study. It did not reach the 0.30 cut-off required for any of the three factors; this result is also consistent with those from previous studies (Alcorta-Garza et al., 2016; Hojat and LaNoue, 2014; Ward et al., 2009; Wen et al., 2013). Nevertheless, Hojat and LaNoue (2014) recommends that all the items still be maintained. The reasons why this item showed poor results may lie in the different roles that families can play in making important decisions about the patient in different sociocultural contexts; cultural patterns of participation, interpretation, and acceptable ways of family involvement can widely differ across different contexts (Montanari et al., 2015; Williams et al., 2013).

In terms of convergent validity, we found that empathy is significantly correlated with emotional intelligence and resilience measures $(0.201 \mathrm{p}<0.001$, and $0.103 \mathrm{p}<0.05$ respectively). As shown in the literature, emotional intelligence is thought of as a characteristic that facilitates interpersonal relationships because it allows one to be aware of emotions, understand them, manage them in oneself and with others, and to use them for better reasoning (Espinoza-Venegas et al., 2015; Extremera Pacheco, 2004; López-Fernández, 2015). The correlation we found between resilience and empathy is consistent with that described in previous studies (Mathad and Pradhan, 2017). 
Regarding the evaluation of empathy in our study, the overall mean was 118.09 and the figures were higher in women (118.23) compared to men (117.24), although this difference was not statistically significant. Nevertheless, several studies indicate the presence of statistically significant gender differences in empathic attitudes (Fields et al., 2011; Hsiao et al., 2013; Ward et al., 2009; Williams et al., 2016). Gender differences in empathy may be caused, in part, to characteristics related to what society expects from women, because women better perceive the emotions of others and are more likely to provide emotional support (Boyle et al., 2009; Fields et al., 2011; Hsiao et al., 2013; Montanari et al., 2015).

The studies we consulted about nursing students showed that, on average, empathy ranks between 104 and 115 points (Hsiao et al., 2013; McMillan and Shannon, 2011; Montanari et al., 2015; Ward et al., 2009), which is lower than the figures we obtained in our work. However, the data are similar when its compared to Spanish medical students (Alcorta-Garza et al., 2016; Ferreira-Valente et al., 2016), thus these dissimilarities are likely because of cultural differences in the value assigned to empathy in Spain compared to other countries. Hojat and Gonnella (2015), in a study carried out on medical students using the JSE-S scale, proposed that the cut-off points are non-definitive and should be confirmed in future studies (Hojat and Gonnella, 2015). In addition, insufficient research work is available on the JSE-HPS scale on nurses and nursing students to establish cut-off points.

Despite possible differences in their training, nursing students are usually instructed on the importance of maintaining an empathic relationship with their patients (Brunero et al., 2010). However, because of scientific and technological advances there is growing concern about excessive technification of nursing-degree curricula. Although technological competence is required, there is a risk of focusing too much on the development of these skills, thus downplaying the role of interpersonal relationships in therapeutic processes (Ward et al., 2009).

Some studies point to the tendency of empathy to decrease in students as their clinical competence increases (Ward, 2016) which is cause for concern among teachers. Moreover, there are numerous research projects that propose interventions aimed at enhancing students' empathic skills so that they can better communicate with patients and respond to their needs (Brunero et al., 2010; Cunico et al., 2016; Terney, 2016; Percy and Richardson, 2018). The use of scales such as the JSE-HPS play an important role in evaluating the impact of these interventions or training programs on the acquisition of empathic skills. The availability of appropriate validated instruments in different contexts and languages is important to allow empirical studies on empathic ability and to facilitate the development of empathy-related skills during training and professional activities.

\subsection{Limitations}

Because this study was conducted in a single public institution in one geographic location, its external validity or the capacity for generalization of the findings may be jeopardized. Thus, further research, involving a more diverse group in which the validity and factorial structure of the tool can be confirmed, will be required to address the limitations of this present study.

\subsection{Conclusion and practical implications}

The Spanish version of the JSE-HPS scale has shown good validity and reliability and therefore can be a useful instrument for evaluating empathy in nursing students. The wide diffusion of the JSE-HPS scale and its different validated versions makes it possible to asses empathy in several environments and to compare the results with other studies in different populations.

Empathy and caring are two concepts that are closely related and linked to nurses' ability to understand the needs of patients and offer patient-centered quality care. Empathic relationships have a positive therapeutic influence on the physical, mental, and social well-being of patients. For that reason, in addition to mastering knowledge based on scientific evidence and complex technologies, nursing students must develop empathic skills that favor quality care for patients. Having an instrument to measure empathy, will facilitate the evaluation of results of nursing training programs designed to develop empathy-based skills. However more empirical research is still needed to examine empathy and the factors that contribute to its development, both during nursing education and through professional practice.

\section{Declarations of interest}

None of the authors reports any conflicts of interest.

\section{Contributions}

Study Design: MJD, MDS, RMF.

Data Collection and Analysis: MJD, MG, MDS, RMF, MEL.

Manuscript Writing: MJD, MG, MEL, SY.

\section{Conflicts of interest}

No conflicts of interest have been declared by the author(s).

\section{Funding}

This research did not receive any specific grants from any funding agencies in the public, commercial, or not-for-profit sectors.

\section{Acknowledgements}

The authors like to thank Jefferson Medical College for their advice and permission to use the JSE-HPS for this validation study, also we would like to thank the students for talking the time to complete the questionnaire.

This research did not receive any specific grant from funding agencies in the public, commercial, or not-for-profit sectors.

\section{References}

Alcorta-Garza, A., San-Martín, M., Delgado-Bolton, R., Soler-González, J., Roig, H., Vivanco, L., 2016. Cross-validation of the Spanish HP-version of the jefferson scale of empathy confirmed with some cross-cultural differences. Front. Psychol. 7, 1-9.

Boyle, M., Williams, B., Brown, T., Molloy, A., Mckenna, L., Molloy, L., Lewis, B., 2009. Levels of empathy in undergraduate health science students. Internet J. Med. Educ. $1,1-8$.

Brunero, S., Lamont, S., Coates, M., 2010. A review of empathy education in nursing. Nurs. Inq. 17, 65-74.

Connor, K.M., Davidson, J.R.T., 2003. Development of a new resilience scale: the connordavidson resilience scale (CD-RISC). Depress. Anxiety 18, 76-82.

Cunico, L., Sartori, R., Marognolli, O., Meneghini, A.M., 2016. Developing empathy in nursing students: a cohort longitudinal study. J. Clin. Nurs. 21, 2016-2025.

Davies, K.a., Lane, A.M., Devonport, T.J., Scott, J.a., 2010. Validity and reliability of a Brief emotional intelligence scale (BEIS-10). J. Individ. Differ. 31, 198-208.

Del Canale, S., Louis, D.Z., Maio, V., Wang, X., Rossi, G., Hojat, M., Gonnella, J.S., 2012. The relationship between physician empathy and disease complications: an empirical study of primary care physicians and their diabetic patients in parma. Italy. Acad. Med. 87, 1243-1249.

Espinoza-Venegas, M., Sanhueza-Alvarado, O., Ramírez-Elizondo, N., Sáez-Carrillo, K., 2015. A validation of the construct and reliability of an emotional intelligence scale applied to nursing students. Rev. Lat. Am. Enfermagem 23, 139-147.

Extremera Pacheco, N.F.B.P., 2004. Emotional intelligence, quality of interpersonal relationships and empathy in university students. Clin. Salud 15, 117-137.

Ferreira-Valente, A., Costa, P., Elorduy, M., Virumbrales, M., Costa, M.J., Palés, J., 2016. Psychometric properties of the Spanish version of the Jefferson Scale of Empathy: making sense of the total score through a second order confirmatory factor analysis. BMC Med. Educ. 16, 242.

Fields, S.K., Mahan, P., Tillman, P., Harris, J., Maxwell, K., Hojat, M., 2011. Measuring empathy in healthcare profession students using the Jefferson Scale of Physician Empathy: health provider-student version. J. Interprofessional Care 25, 287-293.

Finfgeld-Connett, D., 2008. Meta-synthesis of caring in nursing. J. Clin. Nurs. 17, 196-204.

Fjortoft, N., Van Winkle, L.J., Hojat, M., 2011. Measuring empathy in pharmacy students. 
Am. J. Pharmaceut. Educ. 75, 109.

Hoffman, M.L., 2002. How automatic and representational Is empathy, and why. Behav. Brain Sci. 25, 38-39.

Hojat, M., 2016. Empathy in Health Professions Education and Patient Care. Springer International, New York

Hojat, M., Gonnella, J.S., 2015. Eleven years of data on the jefferson scale of empathymedical student version (JSE-S): proxy norm data and tentative cutoff scores. Med. Princ. Pract. 24, 344-350.

Hojat, M., LaNoue, M., 2014. Exploration and confirmation of the latent variable structure of the Jefferson scale of empathy. Int. J. Med. Educ. 5, 73-81.

Hojat, M., Mangione, S., Nasca, T.J., Cohen, M.J.M., Gonnella, J.S., Erdmann, J.B., Veloski, J., Magee, M., 2001. The jefferson scale of physician empathy: development and preliminary psychometric data. Educ. Psychol. Meas. 61, 349-365.

Hsiao, C.Y., Tsai, Y.F., Kao, Y.C., 2013. Psychometric properties of a Chinese version of the jefferson scale of empathy-health profession students. J. Psychiatr. Ment. Health Nurs. 20, 866-873.

Jeyashree, K., Kathirvel, S., Prathibha, M.K., 2017. Cross-cultural adaptation of Jefferson scale of empathy-health professions students version: an experience with developing the Tamil translation. Educ. Health Change Learn. Pract. 30, 169-171.

Kelley, J.M., Kraft-Todd, G., Schapira, L., Kossowsky, J., Riess, H., 2014. The influence of the patient-clinician relationship on healthcare outcomes: a systematic review and meta-analysis of randomized controlled trials. PLoS One 9, e94207.

Kemper, K.J., Khirallah, M., 2015. Acute effects of online mind-body skills training on resilience, mindfulness, and empathy. J. Evid. Based. Compl. Altern. Med. 20, 247-253.

Kiersma, M.E., Chen, A.M.H., Yehle, K.S., Plake, K.S., 2013. Validation of an empathy scale in pharmacy and nursing students. Am. J. Pharmaceut. Educ. 77, 1-6.

Kim, S.S., Kaplowitz, S., Johnston, M.V., 2004. The effects of physician empathy on patient satisfaction and compliance. Eval. Health Prof. 27, 237-251.

Leombruni, P., Di Lillo, M., Miniotti, M., Picardi, A., Alessandri, G., Sica, C., Zizzi, F., Castelli, L., Torta, R., 2014. Measurement properties and confirmatory factor analysis of the Jefferson Scale of Empathy in Italian medical students. Perspect. Med. Educ. 3, 419-430.

López-Fernández, C., 2015. Emotional intelligence and interpersonal relationship among nursing students. Educ. Méd. 16, 83-92.

Magalhães, E., Salgueira, A.P., Costa, P., Costa, M.J., 2011. Empathy in senior year and first year medical students: a cross-sectional study. BMC Med. Educ. 11, 52.

Martín de Benito, M., Guzmán Luján, J.F., 2012. Emotional intelligence, self-determined motivation and basic needs satisfaction in sport. Cuad. Psicol. del Deport. 12, 39-44.

Mathad, M.D., Pradhan, B.,R.S.K., 2017. Correlates and predictors of resilience among baccalaureate nursing students. J. Clin. Diagn. Res. 11 JC05-JC08.

McMillan, L.R., Shannon, D.M., 2011. Psychometric analysis of the JSPE nursing student version R: comparison of senior BSN students and medical students attitudes toward empathy in patient care. ISRN Nurs. 1-7 2011.

Montanari, P., Petrucci, C., Russo, S., Murray, I., Dimonte, V., Lancia, L., 2015. Psychometric properties of the Jefferson Scale of Empathy-Health Professional Student's version: an Italian validation study with nursing students. Nurs. Health Sci. 17, 483-491.

Orak, R.J., Farahani, M.A., Kelishami, F.G., Seyedfatemi, N., Banihashemi, S., Havaei, F.,
2016. Investigating the effect of emotional intelligence education on baccalaureate nursing students' emotional intelligence scores. Nurse Educ. Pract. 20, 64-69.

Percy, M., Richardson, C., 2018. Introducing nursing practice to student nurses : how can we promote care compassion and empathy. Nurse Educ. Pract. 29, 200-205.

Petrucci, C., La Cerra, C., Aloisio, F., Montanari, P., Lancia, L., 2016. Empathy in health professional students: a comparative cross-sectional study. Nurse Educ. Today $41,1-5$.

Preusche, I., Wagner-Menghin, M., 2013. Rising to the challenge: cross-cultural adaptation and psychometric evaluation of the adapted German version of the jefferson scale of physician empathy for students (JSPE-S). Adv. Health Sci. Educ. 18, 573-587.

Reichenheim, M.E., Moraes, C.L., 2007. Operationalizing the cross-cultural adaptation of epidemological measurement instruments. Rev. Saude Publica 41, 665-673.

Reynolds, W.J., Scott, B., 2000. Do nurses and other professional helpers normally display much empathy? J. Adv. Nurs. 31, 226-234.

Ryu, H.-R., Bang, K.-S., 2016. A validation study of the Korean version of the jefferson empathy scale for health professionals for Korean nurses. J. Kor. Acad. Nurs. 46, 207-214.

Serrano-Parra, M., Garrido-Abejar, M., Notario-Pacheco, B., Bartolomé-Gutiérrez, R., Solera-Martínez, M., Martínez-Vizcaíno, V., 2013. Validity of the Connor-Davidson resilience scale(10 ítems) in a population of elderly. Enferm. Clin. 23, 14-21.

Suh, D.H., Hong, J.S., Lee, D.H., Gonnella, J.S., H.M, 2012. The Jefferson Scale of Physician Empathy: a preliminary psychometric study and group comparisons in Korean physicians. Med. Teach. 34, 464-468.

Tavakol, S., Dennick, R., Tavakol, M., 2011. Psychometric properties and confirmatory factor analysis of the jefferson scale of physician empathy. BMC Med. Educ. 11, 54.

Terney, M., 2016. Comparison of Empathy Scores in RN-BSN Students before and after Compassionate Care Course Michele Terney Miller Submitted to the Faculty of the Graduate School of Carlow University in Partial Fulfillment of the Requirements for the Degree of Doctor of Nu. The faculty of the Graduate School of Carlow University.

Thomas, L.J., Asselin, M., 2018. Promoting resilience among nursing students in clinical education. Nurse Educ. Pract. 28, 231-234.

Ward, J., 2016. The empathy enigma: does it still exist? Comparison of empathy using students and standardized actors. Nurse Educ. 41, 134-138.

Ward, J., Cody, J., Schaal, M., Hojat, M., 2012. The empathy enigma: an empirical study of decline in empathy among undergraduate nursing students. J. Prof. Nurs. 28 34-40.

Ward, J., Schaal, M., Sullivan, J., Bowen, M.E., Erdmann, J.B., Hojat, M., 2009. Reliability and validity of the Jefferson Scale of Empathy in undergraduate nursing students. J. Nurs. Meas. 17, 73-88.

Wen, D., Ma, X., Li, H., Liu, Z., Xian, B., Liu, Y., 2013. Empathy in Chinese medical students: psychometric characteristics and differences by gender and year of medical education. BMC Med. Educ. 13, 130.

Williams, B., Boyle, M., Howard, S., 2016. Empathy levels in undergraduate paramedic students: a three-year longitudinal study. Nurse Educ. Pract. 16, 86-90.

Williams, B., Brown, T., Boyle, M., Dousek, S., 2013. Psychometric testing of the jefferson scale of empathy health profession students' version with Australian paramedic students. Nurs. Health Sci. 15, 45-50.

Yu, J., Kirk, M., 2009. Evaluation of empathy measurement tools in nursing: systematic review. J. Adv. Nurs. 65, 1790-1806. 